rührt, um die Bildung des arsen- und antimonsauren Natrons und den Contact des letzteren mit dem geschmolzenen Metall zu befördern. Schmilzt man nämlich arsenhaltiges Antimon mit reinem, völlig entwässertem antimonsaurem Natron zusammen, so findet man schon nach wenigen Minuten ziemlich viel Arsensäure in dem antimonsauren Natron, aus welchem eine entsprechende Quantität Antimonsäure reducirt wird; diese Reduction findet ganz unverändert statt, wenn die Schmelzung in einer Atmosphäre von Kohlensäure vorgenommen wird. Man könnte daher statt des Salpeters der Soda antimonsaures Natron beimischen, es ist jedoch einfacher, sich des Salpeters zu bedienen. Enthält nach dieser Schmelzung der Regulus noch eine Spur von Arsenik, so wird dieselbe durch eine wiederholte und ganz in ähnlicher Weise vorgenommene Schmelzung volkommen entfernt.

\title{
$\overline{\underline{ }}$ \\ Ueber einige Derivate des Benzols; nach $A$. Couper *).
}

Läfst man Bromdampf zu siedendem Benzol treten, so entwickelt sich Bromwasserstoff und nach einander bilden sich zwei Brom-Substitutionsproducte, Brombenzol und Dibrombenzol.

Das Brombenzol (Bromphenyl) $\mathrm{C}_{12} \mathrm{H}_{5} \mathrm{Br}$ geht bei $150^{\circ}$ über. Es ist eine farblose, dem Benzol ähnlich riechende Flüssigkeit, die bei $-20^{\circ}$ noch nicht fest wird und deren

*) Compt. rend. XI.V, 230. 
Dampfdichte $=5,631$ gefunden wurde (die berechnete ist 5,4237). Die Zusammensetzung ist :

$\begin{array}{lcc} & \text { gefunden } & \text { berechnet } \\ \text { Kohlenstoff } & 45,40 & 45,86 \\ \text { Wasserstoff } & 3,27 & 3,18 \\ \text { Brom } & 50,84 & 50,94 .\end{array}$

Auf essigsaures Silber wirkt es bei $200^{\circ}$ kaum ein. Mit rauchender Salpetersäure erwärmt wird es zu einer unter $90^{\circ}$ schmelzbaren und unzersetzt verflüchtigbaren krystallinischen Substanz von der Zusammensetzung $\mathrm{C}_{12} \mathrm{H}_{4}\left(\mathrm{NO}_{4}\right) \mathrm{Br}$.

In rauchender Schwefelsäure löst sich das Brombenzol, und die Lösung giebt beim Stehen an der Luft, aus welcher sie Feuchtigkeit anzieht, Krystalle von Sulfobrombenzolsäure. Diese Säure ist sehr zerflielslich. Bei Zusatz von Ammoniak zu ihrer wässerigen Lösung krystallisirt sofort ein in Wasser fast unlösliches Ammoniaksalz von der Zusammensetzung $\mathrm{C}_{12} \mathrm{H}_{5} \mathrm{Br}, 2 \mathrm{SO}_{3}, \mathrm{NH}_{3}$ :

$\begin{array}{lcc} & \text { gefunden } & \text { berechnet } \\ \text { Kohlenstoff } & 27,86 & 28,34 \\ \text { Wasserstoff } & 3,47 & 3,14 \\ \text { Brom } & 31,35 & 31,48 \\ \text { Stickstoff } & 5,67 & 5,51 .\end{array}$

Bei längerer Einwirkung von überschüssigem Brom auf Brombenzol entwickelt sich Bromwasserstoff und Dibrombenzol scheidet sich in Krystallen aus, die man durch Umkrystallisiren aus Aether reinigt. Diese Verbindung ist $\mathrm{C}_{12} \mathrm{H}_{4} \mathrm{Br}_{2}$ :

$\begin{array}{lcc} & \text { gefunden } & \text { berechnet } \\ \text { Kohlenstoff } & 30,30 & 30,50 \\ \text { Wasserstoff } & 1,92 & 1,69 \\ \text { Brom } & - & 67,81 ;\end{array}$

sie krystallisirt in schönen schief-rhombischen Prismen, schmilzt bei $89^{\circ}$ und destillirt ohne Zersetzung bei $219^{\circ}$. Auf essigsaures Silber wirkt sie, doch nur sehr langsam, 
ein, wahrscheinlich unter Bildung des zweifach-essigsauren Aethers des Phenyl-Glycols $\left.\underset{\left(\mathrm{C}_{4} \mathrm{H}_{3} \mathrm{O}_{2}\right)_{2}}{\mathrm{C}_{12} \mathrm{H}_{4}}\right\}_{4}$. Experimental ist letztere Vermuthung noch nicht bestätigt.

\title{
Ueber die Platinmetalle und ihre Behandlung auf trockenem Wege;
}

\author{
von H. Sainte-Claire Deville und H. Debray*).
}

Wir baben versucht, für die Behandlung der Platinerze, die Gewinnung der darin enthaltenen edlen Metalle und das Probiren dieser Erze, neue Verfahrungsweisen in Anwendung zu bringen, die ausschliefslich Reactionen auf trockenem Wege und Benutzung so hoher Temperaturen, wie sie zum Schmelzen so strengflüssiger Substanzen nothwendig sind, zur Grundlage haben. Ehe wir diese Verfahrungsweisen in ihren Einzelnheiten kennen lehren, scheint es uns angemessen, die Eigenschaften zu beschreiben, welche die hier in Betracht kommenden Metalle unter den Umständen zeigen, in welche wir sie bei unseren Versuchen versetzten. Alle in den Platinerzen enthaltenen Elemente haben etwas Gemeinsames in ihrer chemischen Physiognomie, und doch sind unter ihnen Substanzen enthalten, die mit den in chemischer Beziehung sich unähnlichsten Körpern die grölsten Analogieen zeigen, von dem Osnium, das sich den Metalloïden an die Seite stellt, bis zu dem Rhodium, das man ein edleres Metall als das Gold nennen kann. Ihr gemeinsamer Character ist der,

\#) Compt. rend. XLIV, 1101. 